\title{
Status of Cellular Rather Than Humoral Immunity is Correlated with Clinical Outcome of Enterovirus 71
}

\author{
LUAN-YIN CHANG, CHAO A. HSIUNG, CHUN-YI LU, TZOU-YIEN LIN, FU-YUAN HUANG, YU-HAN LAI, YU-PING CHIANG, \\ BOR-LUEN CHIANG, CHIN-YUN LEE, AND LI-MIN HUANG
}

\begin{abstract}
Department of Pediatrics [L.-Y.C., C.-Y.L., Y.-H.L., Y.-P.C., B.-L.C, C.-Y.L, L.-M.H.], National Taiwan University Hospital and National Taiwan University College of Medicine, Taipei 100, Taiwan; Division of Biostatistics and Bioinformatics [C.A.H.], National Health Research Institutes, Miaoli 350, Taiwan; Chang Gung Children's Hospital and Medical College [C.-L.L.], Chang Gung University, Tao-Yuan 333; Department of Pediatrics [F.-Y.H.], Taipei Mackay Memorial Hospital, Taipei 100, Taiwan
\end{abstract}

\begin{abstract}
We valuated specific cellular and humoral immune response of cases of enterovirus 71 (EV71) infection and correlated immune response with clinical outcome. After obtaining informed consent, we enrolled 30 EV71 cases including 7 cases with brainstem encephalitis plus pulmonary edema, 12 cases of CNS (CNS) involvement and 11 uncomplicated cases. We measured antibodies specific to EV71, lymphocyte proliferation response and EV71-stimulated cellular response of Th1/Th2 cytokines and chemokines. The 7 EV71 cases involving brainstem encephalitis plus pulmonary edema had a significantly lower phytohemagglutinin stimulation index than other cases $(p=0.04)$. After EV71 stimulation of peripheral mononuclear cells, there was a significant increase in cellular Th1 cytokine $(\gamma$ interferon) and proinflammatroy cytokines. However, cases with pulmonary edema had significantly lower cellular $\gamma$-interferon $(p=$ $0.04)$, lower cellular IL-1 $\beta$ ( $p=0.04)$, lower cellular IL-6 $(p=$ $0.04)$, lower cellular tumor necrosis factor- $\alpha$ response $(p=0.04)$, and lower cellular macrophage inflammatory protein- $1 \alpha(p=0.04)$ response compared with other cases. Their titers of EV71 neutralizing antibodies demonstrated no difference among cases. These results suggest lower EV71-specific cellular response may be associated with immunopathogenesis of EV71-related pulmonary edema. (Pediatr Res 60: 466-471, 2006)
\end{abstract}

$\mathrm{O}$ utbreaks of enterovirus 71 (EV71) encephalitis have been reported from the United States, Europe, Australia, Japan, Brazil and Malaysia (1-10), since it was originally characterized from a 1969 California outbreak (1). Before 1998, there were three large outbreaks with dozens of fatal cases occurring in Bulgaria, Hungary, and Malaysia (1975, 1978, and 1997, respectively) (3,5,10). The largest and most severe EV71 epidemic to date occurred in Taiwan in 1998 (11-16). A total of 129,106 cases of hand-foot-and-mouth disease and herpangina (HFMD/HA) were reported (15). Severe neurologic complications and/or pulmonary edema were reported in 405 cases, and 78 children died (15).

Received December 13, 2005; accepted May 22, 2006.

Correspondence: Li-Min Huang, M.D., Ph.D., Division of Infectious Diseases, Department of Pediatrics, National Taiwan University Hospital and National Taiwan University College of Medicine, No.7, Chung-Shan South Road, Taipei 100, Taiwan; e-mail: lmhuang@ha.mc.ntu.edu.tw

Supported by grants from the National Research Program for Genomic Medicine, National Science Council, Taiwan (NSC 93-3112-B-002-024 and NSC 94-3112-B-002028) and the Center for Disease Control, Taiwan.
Most EV71 fatalities were cases of fulminant pulmonary edema (15). However, EV71 infection causes very diverse symptoms, ranging from none (about $71 \%$ ) to fatality (about $0.05 \%)(17,18)$. It remains unknown why different hosts of the same EV71 infection have such a range of clinical outcomes $(17,18)$. Perhaps this range is related to virulence or load of the virus, or particular host factors. To date no relationship has been found between EV71 genotypes and clinical outcome $(19,20)$, and EV71 virulence factors have not been clarified. It is possible that host factors, especially host immune response, may be of ultimate importance to clinical outcome.

To clarify severe EV71 infection pathogenesis, we investigated factors of cellular versus humoral immune response and correlated this with clinical outcome.

\section{SUBJECTS AND METHODS}

Subjects. After National Taiwan University Hospital Research Ethics Committee approved this study and informed parental consent was obtained, 30 EV71 cases of different severity were enrolled. EV71 infection was confirmed by positive EV71 isolation and/or positive EV71 specific IgM at the onset of their disease.

The CNS involvement was indicated in four types of cases. Those with aseptic meningitis had headache and irritability along with cerebrospinal fluid (CSF) pleocytosis ( $>5$ leukocytes $/ \mu \mathrm{L})$ and without an altered level of consciousness. The second type of cases involved encephalitis had altered level of consciousness plus cerebrospinal fluid (CSF) pleocytosis. Poliomyelitislike syndrome was defined as acute limb weakness and decreased reflex and muscle strength. Finally, cases with encephalomyelitis had the occurrence of both encephalitis and poliomyelitis-like syndrome.

Laboratory studies. EV71-specific Humoral Immunity: For EV71-specific humoral immunity, EV71 neutralization antibody and IgM were measured. EV71 IgM was measured at the onset of disease and EV71 neutralization antibody was evaluated at the same time with the measurement of cellular immunity. The laboratory method for measuring EV71 neutralizing antibody followed the standard protocol of neutralization test in microtiter plates (21). Serum samples were inactivated at $56^{\circ} \mathrm{C}$ for $30 \mathrm{~min}$ and then serially diluted from 2- to 1,024-fold. We mixed and incubated $\left(37^{\circ} \mathrm{C}, 2 \mathrm{~h}\right) 50 \mu \mathrm{L}$ of each diluted serum with $50 \mu \mathrm{L}$ containing one hundred $50 \%$ tissue culture infective dose $\left(\mathrm{TCID}_{50}\right)$ of EV71 strain TW/2272/98 (GenBank accession number

Abbreviations: EV71, enterovirus 71; IP-10, interferon $\gamma$-inducible protein10; MCP, monocyte chemoattractant protein; MIP, macrophage inflammatory protein; PHA, phytohemagglutinin; RANTES, regulated on activation, normal $\mathrm{T}$ expressed and secreted; $\mathbf{T C I D}_{\mathbf{5 0}}, \mathbf{5 0 \%}$ tissue culture infective dose

DOI: 10.1203/01.pdr.0000238247.86041.19 
AF119795) in microtiter plates (19) Two replicate wells were used per serum dilution. Then microtiter plates were seeded with $100 \mu \mathrm{L}$ of rhabdomyosarcoma cells $\left(8 \times 10^{4}\right.$ cells per $\left.\mathrm{mL}\right)$ and incubated $\left(37^{\circ} \mathrm{C} 5 \% \mathrm{CO}_{2}\right.$ atmosphere, 2-7 d). Each test was run with cell control, serum control and virus back titration with $100-0.1 \mathrm{TCID}_{50}$. Cytopathic effect was observed under an inverted microscope after incubation, and serotiter was determined when Cytopathic effect was observed in $1 \mathrm{TCID}_{50}$ of the virus back titration. Microtiter plates were fixed with 5\% glutaraldehyde and stained with $0.1 \%$ crystal violet. Seropositivity was defined as serotiter $\geq 8$. For EV71 IgM detection, EV71 isolate TW/2086/98 was amplified and purified as an antigen for use in $\mu$-capture ELISA, whose sensitivity and specificity was $91.5 \%$ and $93.1 \%$, respectively $(22)$.

Cellular immunity: Proliferation response, cellular Th1/Th2 cytokine and chemokine response. To isolate peripheral blood mononuclear cells (PBMCs), blood samples were heparinized and subjected to Ficoll-Hypaque (Pharmacia Diagnostics AB, Uppsala, Sweden) gradient centrifugation. Cells at the interface were removed carefully and washed twice with PBS. The isolated PBMCs were cultured in 96-well round-bottom microplates $\left(3 \times 10^{5}\right.$ cells per well in $0.2 \mathrm{~mL}$ of culture medium) in RPMI 1640 medium supplemented with $1 \mathrm{mM}$ glutamine, $1 \mathrm{mM}$ sodium pyruvate, $50 \mu \mathrm{M} 2$-ME, $100 \mathrm{U} / \mathrm{mL}$ penicillin, $0.1 \mathrm{mg} / \mathrm{mL}$ streptomycin, and $2 \%$ human $\mathrm{AB}$ serum (Biocell Laboratories Inc., Rancho Domingnez, CA).

In addition, PBMCs were stimulated with phytohemagglutinin (PHA) $(8$ $\mu \mathrm{g} / \mathrm{mL}$ ) or different concentrations of EV71 whole virus antigen $(1,5$, and 10 $\mu \mathrm{g} / \mathrm{mL}$ ) TW/2272/98 (GenBank accession number AF119795) or in the absence of antigen (served as the control). EV71 whole virus antigen was purified by $15-45 \%$ sucrose gradient centrifugation $(25,000 \mathrm{rpm}$ for $4 \mathrm{~h}$ at $4^{\circ} \mathrm{C}$ ) and the concentration of virus was measured by use of Bio-Rad protein assay reagents.

After $3 \mathrm{~d}$ of incubation, supernatant was collected and assayed for production of Th1/Th2 (T helper 1/T helper 2) cytokines ( $\gamma$-interferon, IL-1 $\beta$, IL-2, IL-4, IL-5, IL-6, IL-10, IL-13 and TNF- $\alpha$ ) and chemokines (eotaxin, IL-8, IP-10, MCP-1, MCP-2, MCP-3, MCP-4, MIP-1 $\alpha$ and RANTES), which were measured with protein array kits (Fast Quant Microspot Assay, Shleicher \& Schuell, Dassel, Germany). All the assays were triplicate. The detectable levels for IL (interleukin)-1 $\beta$, IL-2, IL-4, IL-5, IL-6, IL-10, IL-13, $\gamma$-interferon and TNF- $\alpha$ (tumor necrosis factor- $\alpha$ ) were $3-3,000,3-3,000,4-3,000$, $10-3,000,3-3,000,30-12,000,100-12,000,30-12,000$, and $4-3,000 \mathrm{pg} /$ $\mathrm{mL}$, respectively. The detectable level for IP-10 (interferon $\gamma$-inducible protein-10) was $12.2-12,500 \mathrm{pg} / \mathrm{mL}$ and that for eotaxin, IL-8, MCP (monocyte chemoattractant protein)-1, MCP-2, MCP-3, MCP-4, MIP (macrophage inflammatory protein)- $1 \alpha$ and RANTES (regulated on activation, normal T expressed and secreted) was $2.4-2,500 \mathrm{pg} / \mathrm{mL}$ respectively.

Proliferation response was measured at the end of the culture period. After $6 \mathrm{~d}$ of culture, $1 \mathrm{mCi}$ of ${ }^{3} \mathrm{H}$-thymidine (Amersham, Buckinghamshire, England) was added to each well for $18 \mathrm{~h}$, and the incorporated radioactivity was measured by $\beta$-counter (Parkard Instrument Co., Inc., Meriden, CT). Data are taken from triplicate wells as mean number of counts per minute (cpm). Stimulation index was calculated by the formula of the $\mathrm{cpm}$ incorporated in response to antigen divided by the cpm incorporated in the absence of antigen. In each time of lymphocyte proliferation response, PBMCs of one healthy individual were stimulated with phytohemagglutinin (PHA) $(8 \mu \mathrm{g} / \mathrm{mL})$ and used as the experimental control, and their PHA stimulation index was ranged from $8-45$.

Statistics. Data were analyzed with SAS Statistical Package (Version 9.1, SAS Institute, Cary, NC). Because there was limited case number and values were not distributed normally, we used Kruskal-Wallis test and MannWhitney $U$-test for continuous variables. $\chi^{2}$ test was used for categorical data. Wilcoxon signed rank test was used to compare cellular cytokine and chemokine response with or without EV71 antigen stimulation. To prevent the confounding effects of age and sex on the immune response, multiple logistic regression analysis was used to calculate the adjusted $\mathrm{p}$ values for cellular and humoral immunity after concomitant adjustment of age and sex. $p<0.05$ was considered statistically significant.

\section{RESULTS}

Clinical syndromes and outcomes. Immune work-up was completed with 30 EV71 cases. This included 7 cases with brainstem encephalitis plus pulmonary edema, 12 cases of CNS (CNS) involvement including 5 of septic meningitis, 5 of encephalitis, 1 of poliomyelitis-like syndrome and 1 of encephalomyelitis, and 11 uncomplicated cases of hand-footand-mouth disease or herpangina. In 22 cases, we isolated the virus itself, and detected positive IgM of EV71; the remaining 8 cases were negative for the virus but positive for EV71 IgM at the onset of disease. Their median (range) age at the onset of disease was $0.55(0.16-1.6)$ year for the 7 cases with brainstem encephalitis plus pulmonary edema, 2.4 (1.3-4.5) years for 12 cases of CNS involvement and $1.8(0.37-5.0)$ years for 11 uncomplicated cases; the age at the onset of disease was significantly younger for the group with brainstem encephalitis plus pulmonary edema than the other two groups $(p=0.007$ with Kruskal-Wallis test). The male-to-female ratio was 3:4 for the 7 cases with brainstem encephalitis plus pulmonary edema, 7:5 for 12 cases with CNS involvement and 6:5 for the 11 uncomplicated cases $\left(p=0.80\right.$ with $\chi^{2}$ test). The median (range) interval between their disease onset and enrollment in this study was not significantly different among the three groups: $1.9(1.1-2.9)$ years for the 7 cases with brainstem encephalitis plus pulmonary edema, $2.5(0.7-5.2)$ years for 12 cases with CNS involvement, and $2.6(0.7-2.7)$ for 11 uncomplicated cases $(p=0.17$ with Kruskal-Wallis test). The median (range) age at this immune study was 3.1 (1.7-3.8) years for the 7 cases with brainstem encephalitis plus pulmonary edema, $5.8(3.5-7.3)$ years for 12 cases with CNS involvement, and $4.5(2.0-8.1)$ years for 11 uncomplicated cases ( $p=0.005$ with Kruskal-Wallis test).

Among the seven cases of brainstem encephalitis plus pulmonary edema, one recovered completely, one had sequelae of right upper-limb paralysis plus scoliosis, and five had polio-like sequelae and hypoventilation with ventilator support. All remaining 11 cases of CNS involvement as well as the 12 uncomplicated cases recovered without neurologic sequelae.

EV71-specific neutralizing antibody titers. EV71-specific humoral immunity is shown in Fig. 1, and neutralizing antibody titers did not differ significantly among all the three groups of different severity $(p=0.567$ with Kruskal-Wallis test). Age $<3$ y and gender did not affect the neutralizing antibody titers significantly, either $(p=0.68$ and $p=0.83$ with Mann-Whitney $U$-test, respectively).

Cell-mediated Immunity. PHA-stimulation index is shown in Fig. 2. EV71 cases with pulmonary edema had significantly lower PHA-stimulated lymphocyte proliferation (median

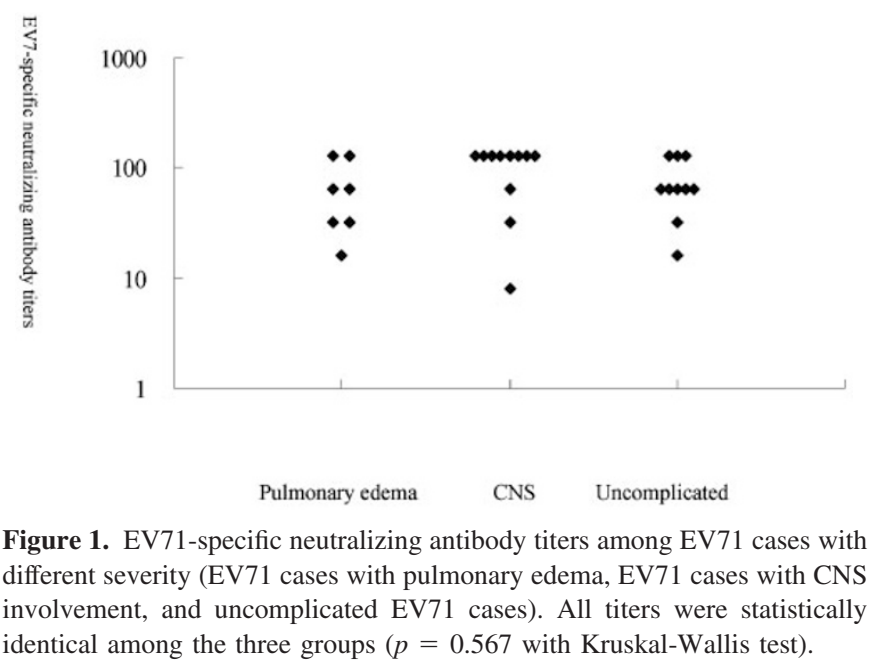




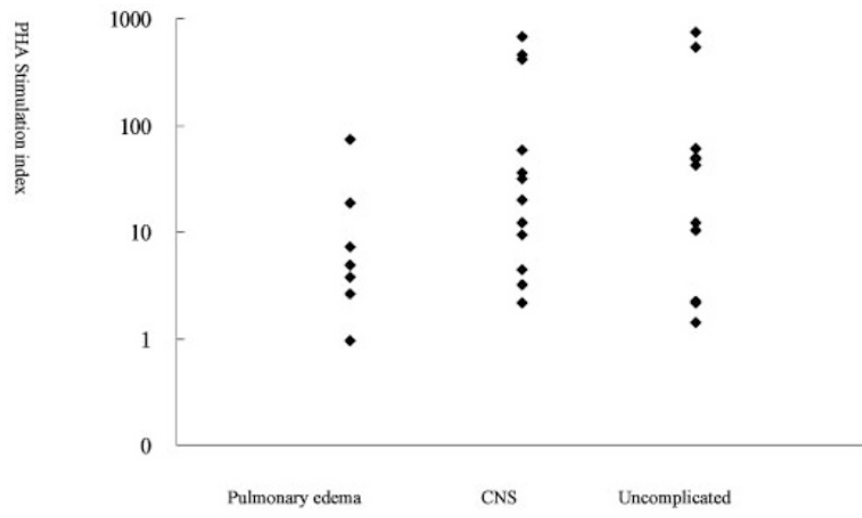

Figure 2. PHA stimulation index among EV71 cases with different severity (EV71 cases with pulmonary edema, EV71 cases with CNS involvement, and uncomplicated EV71 cases). EV71 cases with pulmonary edema had a significantly lower PHA stimulation index ( $p=0.04$, measured to compare the percentages of a response over the median level of increase of all the EV71 cases by using likelihood ratio $\chi^{2}$ test).

PHA-stimulated index 4.95, range 0.94-72.96) in comparison with the other EV71 cases (median PHA-stimulated index 31.8 , range 1.39-740.8). The median PHA-stimulated index of all 30 cases was 19 . Only one (14\%) of the pulmonary edema cases had a PHA-stimulated index over $19(p=0.04$ with $\chi^{2}$ test), whereas 13 (57\%) of non-pulmonary edema cases did. Age $<3$ y and gender did affect the PHAstimulation index significantly $\left(p=0.89\right.$ and $p=0.48$ with $\chi^{2}$ test, respectively). After adjusted with age and gender, cases of pulmonary edema was still significantly associated with lower rate of PHA-stimulated index over 19 ( $p=0.02$ with multiple logistic regression analysis).

EV71 stimulation index was dose-related. Higher doses of EV71 antigen stimulation induce higher lymphocyte proliferation response. Although EV71-specific lymphocyte proliferation was higher in uncomplicated cases, no statistical difference in lymphocyte proliferation was found between pulmonary edema cases and other cases $(p=0.48, p=0.33$, $p=0.59$ for EV71 concentration 1,5 , or $10 \mu \mathrm{g} / \mathrm{mL}$, respectively). The highest EV71 stimulation index levels are shown in Fig. 3. The median EV71-stimulated index of all 30 cases

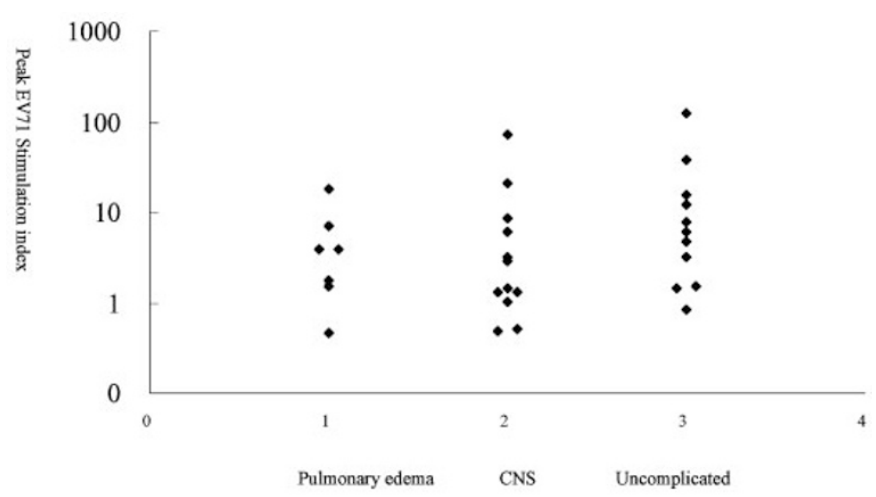

Figure 3. Peak enterovirus 71 (EV71) stimulation index among EV71 cases with different severity (EV71 cases with pulmonary edema, EV71 cases with CNS involvement, and uncomplicated EV71 cases). All peak EV71 stimulation index were statistically identical among the three groups ( $p=0.31$ with Kruskal-Wallis test) was 3.59. Four (57\%) of the 7 pulmonary edema cases had an EV71-stimulated index over 3.59, whereas 11 (48\%) of 23 non-pulmonary edema cases did $\left(p=0.95\right.$ with $\chi^{2}$ test). Overall only $60 \%(18 / 30)$ had peak EV71 SI $>=2$, and included $4(57 \%)$ of pulmonary edema cases, $6(50 \%)$ of CNS cases, and $8(73 \%)$ of uncomplicated cases $\left(p=0.53\right.$ with $\chi^{2}$ test). Age $<3$ y and gender did affect the EV71-stimulation index significantly $\left(p=0.11\right.$ and $p=0.47$ with $\chi^{2}$ test, respectively), either.

Cellular cytokine and chemokine response after EV71 stimulation. Difference in the cytokine and chemokine response of peripheral mononuclear cells with and without EV71 antigen stimulation is shown in Table 1. In comparison with condition of absence of EV71 antigen, EV71 antigen stimulation induced a significant increase in cellular Th1 cytokine ( $\gamma$-interferon) but a significant decrease in Th2 cytokine (IL-5). There were a $\gamma$-interferon median increase of 42 $\mathrm{pg} / \mathrm{mL}$ and an IL-5 median decrease of $1.45 \mathrm{pg} / \mathrm{mL}$. As well, there was an increase of the pro-inflammatory cytokines IL-6 (median increase, $500 \mathrm{pg} / \mathrm{mL}$ ), IL-1 $\beta$ (median increase, 36 $\mathrm{pg} / \mathrm{mL}$ ), and TNF- $\alpha$ (median increase, $86 \mathrm{pg} / \mathrm{mL}$ ). Overall, EV71 stimulation had a positive effect on cellular Th1 cytokine and pro-inflammatory cytokine response, but no effect or a mildly negative effect on Th2 cytokines.

Table 1. The difference in peripheral mononuclear cellular cytokine and chemokine response with and without EV71 antigen stimulation

\begin{tabular}{lcc}
\hline Cytokine or chemokine & $\begin{array}{c}\text { Median (range) } \\
\text { difference }(\mathrm{pg} / \mathrm{mL})\end{array}$ & $\begin{array}{c}P \text {-value with Wilcoxon } \\
\text { signed rank test }\end{array}$ \\
\hline Th1 cytokine & $42(-19-6,541)$ & $<0.001$ \\
$\gamma$-interferon & $1.1(-62-138)$ & $\mathrm{NS}$ \\
Interleukin-2 & & $\mathrm{NS}$ \\
Th2 cytokine & $-3.9^{*}(-137-289)$ & $<0.022$ \\
Interleukin-4 & $-1.45^{*}(-14-8)$ & $\mathrm{NS}$ \\
Interleukin-5 & $0(-2,713-1,123)$ & $\mathrm{NS}$ \\
Interleukin-10 & $99(-1,239-4,211)$ & \\
Interleukin-13 & & $<0.001$ \\
Pro-inflammatory cytokine & $36(-73-453)$ & $<0.001$ \\
Interleukin-1 $\beta$ & $500(-1,088-7,170)$ & $<0.001$ \\
Interleukin-6 & $86(-75-605)$ & \\
TNF- $\alpha$ & & 0.06 \\
Chemokine & $-731^{*}(-1,711-2,027)$ & $\mathrm{NS}$ \\
Interleukin-8 & $0(-35-9)$ & $<0.02$ \\
Eotaxin & $87(0-4,885)$ & $\mathrm{NS}$ \\
IP-10 & $8.3(-2,038-3,373)$ & $<0.001$ \\
MCP-1 & $1,051(0-5,881)$ & $<0.001$ \\
MCP-2 & $897(-30-2,527)$ & $<0.05$ \\
MCP-3 & $7.25(-57-59)$ & $<0.001$ \\
MCP-4 & $1,635(-1,020-5,266)$ & 0.043 \\
MIP-1 $\alpha$ & $321(-787-3,184)$ & \\
RANTES & &
\end{tabular}

The numbers in parenthesis are the ranges of the difference for peripheral mononuclear cellular cytokine and chemokine response with and without EV71 antigen stimulation.

* The "“" denotes decreased response after EV71 stimulation. $P$-values were measured to compare the difference of cellular cytokine/chemokine response with or without EV71 antigen stimulation by using Wilcoxon signed rank test.

NS, not significant; TNF- $\alpha$, tumor necrosis factor-alpha; IP, interferon $\gamma$-inducible protein; MCP, monocyte chemoattractant protein; MIP, macrophage inflammatory protein; RANTES, regulated on activation, normal T expressed and secreted. 
After EV71 stimulation, certain cellular chemokine responses significantly increased, including IP-10 (median increase, $87 \mathrm{pg} / \mathrm{mL}$ ), MCP-2 (median increase, $1,051 \mathrm{pg} / \mathrm{mL}$ ), MCP-3 (median increase, $897 \mathrm{pg} / \mathrm{mL}$ ), MCP-4 (median increase, $7.25 \mathrm{pg} / \mathrm{mL}$ ), MIP- $1 \alpha$ (median increase, $1,635 \mathrm{pg} / \mathrm{mL}$ ), and RANTES (median increase, $325 \mathrm{pg} / \mathrm{mL}$ ).

After observing the significant increase in cellular response of $\gamma$-interferon, IL-1 $\beta$, IL-6, TNF- $\alpha$, IP-10, MCP-2, MCP-3, MCP-4, MIP- $1 \alpha$ and RANTES, and the significant decrease in IL-5, we compared the cellular response of these cytokines/ chemokines with severity of cases. Cases with pulmonary edema were found to have significantly lower cellular $\gamma$-interferon (Fig. 3; $p=0.04$ ), lower cellular IL-1 $\beta$, lower cellular IL-6, lower cellular TNF- $\alpha$ response and lower cellular MIP-1A response in comparison with other EV71 cases. In cases with pulmonary edema the percentage of increase over the median level of cellular $\gamma$-interferon, IL- $1 \beta$, IL-6, TNF- $\alpha$ and MIP- $1 \alpha$ was lowest (Table 2). Uncomplicated EV71 cases had highest percentages of increase over the median level of cellular $\gamma$-interferon, IL- $1 \beta$, IL- 6 , and TNF- $\alpha$ (Table 2). Age and gender did not affect their cellular cytokine response significantly. After age and gender adjustment, the percentage of increased cellular cytokines was still significantly different among the three groups with different clinical severity ( $p=0.02$ for $\gamma$-interferon, IL- $1 \beta$, IL- 6 , and TNF- $\alpha$ ) (Fig. 4).

In contrast, $67 \%(8 / 12)$ cases with CNS involvement and $64 \%$ (7/11) uncomplicated cases had decrease over the median level of cellular IL-5 response after EV71 stimulation whereas none of the pulmonary edema cases had decrease of cellular IL-5 response $(p=0.01)$. In general, EV71 antigen enhanced cellular Th1 cytokine, pro-inflammatory cytokine and chemokine response, and reduced cellular Th2 cytokine (IL-5) response in most cases of CNS involvement and uncomplicated cases. However, EV71 antigen had little effect on cellular cytokine and chemokine response in most cases with brainstem encephalitis plus pulmonary edema.

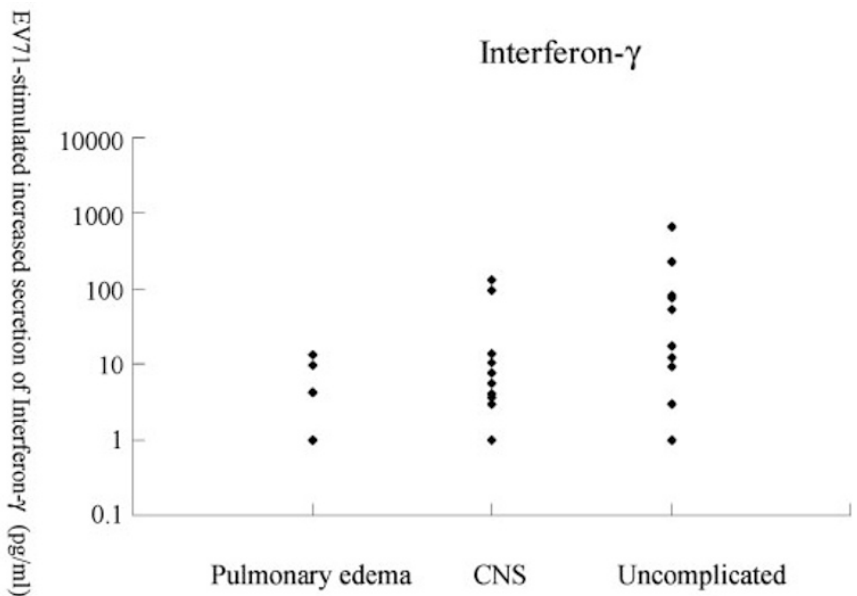

Figure 4. Cellular interferon- $\gamma$ response after EV71 stimulation at the concentration of $10 \mu \mathrm{g} / \mathrm{mL}$ ) among EV71 cases with different severity (EV71 cases with pulmonary edema, EV71 cases with CNS involvement, and uncomplicated EV71 cases). EV71 cases with pulmonary edema had significantly lower interferon- $\gamma$ response than the other EV71 cases $(p=0.04$, measured to compare the percentages of a response over the median level of increase of all the EV71 cases by using likelihood ratio $\chi^{2}$ test).

\section{DISCUSSION}

This study suggests that cellular immunity rather than humoral immunity may be associated with the clinical outcome of EV71 infections. Age and gender may influence the immunity, however we demonstrate cellular immunity (PHA stimulation index) and cellular cytokine ( $\gamma$-interferon, IL-1 $\beta$, IL-6, and TNF- $\alpha$ ) response were significantly weaker in EV71 cases with pulmonary edema than the other EV71 cases after age and gender adjustment. On the contrary, the humoral immunity (EV71-specific neutralizing antibody) did not differ significantly among cases with different clinical severity. This study was an exploratory study with the small number of the cases and was not investigated prospectively, so the results

Table 2. The percentage of cases with a response above the median level after EV71 stimulation among EV71 cases with different severity

\begin{tabular}{|c|c|c|c|c|}
\hline $\begin{array}{l}\text { A response above the median } \\
\text { level after EV71 stimulation }\end{array}$ & $\begin{array}{l}\text { Pulmonary edema } \\
(\mathrm{N}=7)\end{array}$ & $\begin{array}{l}\text { CNS involvement } \\
(\mathrm{N}=12)\end{array}$ & $\begin{array}{l}\text { Uncomplicated cases } \\
\qquad(\mathrm{N}=11)\end{array}$ & $P$-value \\
\hline \multicolumn{5}{|l|}{ Th1 Cytokine } \\
\hline$\gamma$-interferon $>42 \mathrm{pg} / \mathrm{mL}$ & $1(14 \%)$ & $5(42 \%)$ & $8(73 \%)$ & 0.04 \\
\hline Interleukin-5 $<-1.45 \mathrm{pg} / \mathrm{mL}^{*}$ & 0 & $8(67 \%)$ & $7(64 \%)$ & 0.01 \\
\hline \multicolumn{5}{|l|}{ Pro-inflammatory cytokine } \\
\hline Interleukin- $1 \beta>36 \mathrm{pg} / \mathrm{mL}$ & $1(14 \%)$ & $5(42 \%)$ & $8(73 \%)$ & 0.04 \\
\hline \multicolumn{5}{|l|}{ Chemokine } \\
\hline IP- $10>87 \mathrm{pg} / \mathrm{mL}$ & $1(14 \%)$ & $7(58 \%)$ & $4(36 \%)$ & 0.14 \\
\hline MCP-2 $>1051 \mathrm{pg} / \mathrm{mL}$ & $1(14 \%)$ & $6(50 \%)$ & $5(45 \%)$ & 0.24 \\
\hline MCP-3 >897 pg/mL & $1(14 \%)$ & $6(50 \%)$ & $5(45 \%)$ & 0.24 \\
\hline MCP- $4>7.25 \mathrm{pg} / \mathrm{mL}$ & $1(14 \%)$ & $6(50 \%)$ & $5(45 \%)$ & 0.24 \\
\hline MIP- $1 \alpha>1635 \mathrm{pg} / \mathrm{mL}$ & $1(14 \%)$ & $8(67 \%)$ & $3(27 \%)$ & 0.04 \\
\hline
\end{tabular}

* The "-" denotes decreased response after EV71 stimulation. $P$-value was measured to compare the percentages of cases with a response above the median level by using likelihood ratio $\chi^{2}$ test among the three groups.

TNF- $\alpha$, tumor necrosis factor-alpha; IP, interferon $\gamma$-inducible protein; MCP, monocyte chemoattractant protein; MIP, macrophage inflammatory protein; RANTES, regulated on activation, normal $\mathrm{T}$ expressed and secreted. 
must be validated by further prospective immunologic studies in EV71 cases or host immune genetic studies.

In the most severe EV71 cases with pulmonary edema there is lower cellular Th1 cytokine coupled with a lower lymphocyte proliferation response. Higher incidence of most severe EV71 diseases were found in children under $3 \mathrm{y}$ of age $(15,16)$, and this might be explained by their weaker cellular immunity. We hypothesize that lower cellular immunity may delay viral killing or clearance, thus resulting in viral dissemination, sustained systemic inflammatory response and subsequent pulmonary edema. Host genetic factors may also play an important role and will require further investigation. Yang KD et al. reported that patients with EV 71 meningoencephalitis had a higher frequency of $\mathrm{G} / \mathrm{G}$ genotype with a polymorphism of the cytotoxic T lymphocyte antigen- 4 at position 49 of exon 1 than did control subjects without meningoencephalitis. In these cases there was no difference in specific EV 71 neutralizing antibody titers in the 2 groups (23). In our study, humoral immunity did not affect the clinical outcome of EV71 infection, either. Results from the two studies suggest that younger children with genetics involving decreased cellular rather than humoral response may be linked to severe EV 71 infection.

In this study control for differences in the ages of patients was tried in each of three presentations, but truly valid conclusions regarding differences in cell-mediated immune response in the brainstem encephalitis plus pulmonary edema group can only be established using age matched controls in the CNS involvement and uncomplicated disease groups. Another query is whether maternal EV71 could have been important in later cellular immune response antibody making the lower cellular EV71 immune response of the youngest subjects, as maternal antibody might be after administration of live viral vaccines. However, we had a seroepidemiology study, done in 1999 (18), which showed that 94\% (177/189) of 3- to 6-month-old children and $92 \%$ (265/287) of 7- to 12 month-old children did not have EV71 neutralizing antibody. The $8 \%$ of 7- to 12-month-old children might get their antibody through natural EV71 infection rather than maternal antibody. The results suggested that even the youngest group of EV71 cases seldom had maternal EV71 antibody, so their lower cellular immunity might be related to other causes rather than maternal antibody.

Our previous studies reported that patients with pulmonary edema had dramatically high blood values of IL-1 $\beta$, IL-6, tumor necrosis factor- $\alpha$, white blood cell counts, and glucose levels $(24,25)$. These findings suggest that a combination of CNS and systemic inflammatory response may trigger EV71related cardiopulmonary collapse (24). Another study of patients with pulmonary edema showed significant immunomodulator elevation as well as lower circulating $\mathrm{CD}^{+}$ T-cells, CD8 ${ }^{+}$T-cells, and natural killer cells (26). They also suggested that the combination of an extensive systemic and CNS inflammatory response and lymphocyte depletion appears to be responsible for the pathogenesis of EV71associated pulmonary edema (26).

Suggested treatments have varied. Since those cases with pulmonary edema had lower cellular immunity, a rational treatment may involve regimens to enhance cellular immunity. In the case of poliomyelitis, IFN- $\gamma$ treatment of age-dependent poliomyelitis-susceptible mice protected them from paralytic disease (27). Recent studies have also shown that interferon- $\gamma$ synergizes with IFN- $\alpha / \beta$ to inhibit the replication of both RNA and DNA viruses. Scagnolari et al. investigated the effects of IFNs on the replication of severe acute respiratory syndrome-associated coronavirus (SARS-CoV), finding that although SARS-CoV is only moderately sensitive to IFN- $\beta$ and weakly sensitive to IFN- $\alpha$ and IFN- $\gamma$, in combination they have a strong synergistic effect on virus replication (28). These two studies imply treatments for severe EV71 infection, but further animal or clinical trial is mandatory to prove the efficacy of immunomodulators. In addition, use of an antiviral agent to decrease replication may also be beneficial (29). Animal studies are ongoing on this topic. In the Liu et al. study, an early administration of recombinant mouse interferon- $\alpha$ protected the mice against EV71 infection and in vitro analysis of virus-induced death showed that human type I interferons exerted a direct protective effect on EV71, so interferons may play an important role in controlling EV71 infection and replication (30).

Currently there is no vaccine for EV71. Since the major cytokine response of mononuclear cells after EV71 challenge is Th1 cytokines, induction of Th1 cellular response may be critical to vaccine development for prevention of severe EV71 disease. Therefore, an ideal vaccine should trigger adequate immunity in both cellular and humoral systems.

In conclusion, we found that cellular immunity rather than humoral immunity may be related to the clinical outcome of EV71 infections. EV71 cases with decreased cellular immunity plus lower cellular $\gamma$-interferon and other cytokine/ chemokine response may be prone to disseminated EV71 infection and subsequent pulmonary edema.

\section{REFERENCES}

1. Schmidt NJ, Lennette EH, Ho HH 1974 An apparently new enterovirus isolated from patients with disease of the central nervous system. J Infect Dis 129:304-309

2. Blomberg J, Lycke E, Ahlfors K, Johnsson T, Wolontis S, von Zeipel G 1974 New enterovirus type associated with epidemic of aseptic meningitis and/or hand, foot, and mouth disease. Lancet 2:112

3. Shindarov LM, Chumakov MP, Voroshilova MK, Bojinov S, Vasilenko SM, Iordanov I, Kirov ID, Kamenov E, Leshchinskaya EV, Mitov G, Robinson IA, Sivchev S, Staikov S 1979 Epidemiological, clinical and pathomorphological characteristics of epidemic poliomyelitis-like disease caused by enterovirus 71 . J Hyg Epidemiol Microbiol Immunol 23:284-295

4. Ishimaru Y, Nakano S, Yamaoka K, Takami S 1980 Outbreaks of hand, foot, and mouth disease by enterovirus 71: high incidence of complication disorders of central nervous system. Arch Dis Child 55:583-588

5. Nagy G, Takatsy S, Kukan E, Mihaly I, Domok I 1982 Virological diagnosis of enterovirus type 71 infections: experiences gained during an epidemic of acute CNS diseases in Hungary in 1978. Arch Virol 71:217-227

6. Melnick JL 1984 Enterovirus type 71 infections: a varied clinical pattern sometimes mimicking paralytic poliomyelitis. Rev Infect Dis 6:S387-S390

7. Gilbert GL, Dickson KE, Waters MJ, Kennett ML, Land SA, Sneddon M 1988 Outbreak of enterovirus 71 infection in Victoria, Australia, with a high incidence of neurologic involvement. Pediatr Infect Dis J 7:484-488

8. Alexander JP, Baden L, Pallansch MA, Anderson LJ 1994 Enterovirus 71 infections and neurologic disease: United States, 1977-1991. J Infect Dis 169:905-908

9. da Silva EE, Winkler MT, Pallansch MA 1996 Role of enterovirus 71 in acute flaccid paralysis after the eradication of poliovirus in Brazil. Emerg Infect Dis 2:231-233

10. Chan LG, Parashar UD, Lye MS, Ong FG, Zaki SR, Alexander JP, Ho KK, Han LL, Pallansch MA, Suleiman AB, Jegathesan M, Anderson LJ 2000 Deaths of children during an outbreak of hand, foot, and mouth disease in Sarawak, Malaysia: Clinical and pathological characteristics of the disease. Clin Infect Dis 31:678-683

11. Chang LY, Huang YC, Lin TY 1998 Fulminant neurogenic pulmonary edema with hand, foot and mouth disease. Lancet 352:367-368 
12. CDC 1998 Deaths among children during an outbreak of hand, foot and mouth disease-Taiwan, Republic of China, April-July 1998. MMWR Morb Mortal Wkly Rep 47:629-632 [Erratum, MMWR. 1998;47:718.]

13. Wu TN, Tsai SF, Li SF, Lee TF, Huang TM, Wang ML, Hsu KH, Shen CY 1999 Sentinel surveillance of enterovirus 71, Taiwan, 1998. Emerg Infect Dis 5:458-460

14. Chang LY, Lin TY, Hsu KH, Huang YC, Lin KL, Hsueh C, Shih SR, Ning HC, Hwang MS, Wang HS, Lee CY 1999 Clinical features and risk factors of pulmonary edema after enterovirus 71-related hand, foot, and mouth disease. Lancet 354:1682-1686

15. Ho M, Chen ER, Hsu KH, Twu SJ, Chen KT, Tsai SF, Wang JR, Shih SR 1999 An epidemic of enterovirus 71 infection in Taiwan. N Engl J Med 341:929-935

16. Huang CC, Liu CC, Chang YC, Chen CY, Wang ST, Yeh TF 1999 Neurological complications in children with enterovirus 71 infection. N Engl J Med 341:936-942

17. Chang LY, Tsao KC, Hsia SH, Shih SR, Huang CG, Chan WK, Hsu KH, Fang TY, Huang YC, Lin TY 2004 Transmission and clinical features of enterovirus 71 infections in household contacts in Taiwan. JAMA 291:222-227

18. Chang LY, King CC, Hsu KH, Ning HC, Tsao KC, Li CC, Huang YC, Shih SR, Chiou ST, Chen PY, Chang HJ, Lin TY 2002 Risk factors of enterovirus 71 infection and associated hand-foot-mouth-disease/herpangina in children. Pediatrics 109:E88

19. Shih SR, Ho MS, Lin KH, Wu SL, Chen YT, Wu CN, Lin TY, Chang LY, Tsao KC, Ning HC, Chang PY, Jung SM, Hsueh C, Chang KS 2000 Genetic analysis of enterovirus 71 isolated from fatal and non-fatal cases of hand, foot and mouth disease during an epidemic in Taiwan, 1998. Virus Res 68:127-136

20. Shimizu H, Utama A, Yoshii K, Yoshida H, Yoneyama T, Sinniah M, Yusof MA, Okuno Y, Okabe N, Shih SR, Chen HY, Wang GR, Kao CL, Chang KS, Miyamura T, Hagiwara A 1999 Enterovirus 71 from fatal and nonfatal cases of hand, foot and mouth disease epidemics in Malaysia, Japan and Taiwan in 1997-1998. Jpn J Infect Dis $52: 12-15$

21. Grandien M, Fosgren M, Ehrnst A 1995 Enterovirus. In: Lennette EH, Lennette DA Lennette ET (eds) Diagnostic Procedures for Viral, Rickettsial and Chlamydial Infections. American Public Health Association: Washington DC, pp 279-298
22. Tsao KC, Chan EC, Chang LY, Chang PY, Huang CG, Chen YP, Chang SC, Lin TY, Sun CF, Shih SR 2002 Responses of IgM for enterovirus 71 infection. J Med Virol 68:574-580

23. Yang KD, Yang MY, Li CC, Lin SF, Chong MC, Wang CL, Chen RF, Lin TY 2001 Altered cellular but not humoral reactions in children with complicated enterovirus 71 infections in Taiwan. J Infect Dis 183:850-856

24. Lin TY, Hsia SH, Huang YC, Wu CT, Chang LY 2003 Pro-inflammatory cytokine reactions in enterovirus 71 infections of the central nervous system. Clin Infect Dis 36:269-274

25. Lin TY, Chang LY, Huang YC, Hsu KH, Chiu CH, Yang KD 2002 Different pro-inflammatory reactions in fatal and non-fatal enterovirus 71 infections: implications for early recognition and therapy. Acta Paediatr 91:632-635

26. Wang SM, Lei HY, Huang KJ, Wu JM, Wang JR, Yu CK, Su IJ, Liu CC 2003 Pathogenesis of enterovirus 71 brainstem encephalitis in pediatric patients: roles of cytokines and cellular immune activation in patients with pulmonary edema. J Infect Dis 188:564-570

27. Cafruny WA, Haven TR, Lawson SR, Wong GH, Rowland RR 1997 Inhibition of virus-induced age-dependent poliomyelitis by interferon-gamma. Antiviral Res $36: 1-9$

28. Scagnolari C, Vicenzi E, Bellomi F, Stillitano MG, Pinna D, Poli G, Clementi M, Dianzani F, Antonelli G 2004 Increased sensitivity of SARS-coronavirus to a combination of human type I and type II interferons. Antivir Ther 9:1003-1011

29. Chern JH, Shia KS, Hsu TA, Tai CL, Lee CC, Lee YC, Chang CS, Tseng SN, Shih SR 2004 Design, synthesis, and structure-activity relationships of pyrazolo[3,4 d]pyrimidines: a novel class of potent enterovirus inhibitors. Bioorg Med Chem Lett 14:2519-2525

30. Liu ML, Lee YP, Wang YF, Lei HY, Liu CC, Wang SM, Su IJ, Wang JR, Yeh TM, Chen SH, Yu CK 2005 Type I interferons protect mice against enterovirus 71 infection. J Gen Virol 86:3263-3269 